\title{
Otomobil Isı Pompası Sistemlerinde R152a'nın Kullanımında Çevre ve Akış Şartlarının Sistem Performansı Üzerine Etkisi
}

\author{
Mehmet DİREK*(i), Fikret YÜKSEL \\ Yalova Üniversitesi Mühendislik Fakültesi, Enerji Sistemleri Mühendisliği, Yalova
}

Geliş / Received: 28/05/2018, Kabul / Accepted: 18/12/2018

\begin{abstract}
Öz
Bu çalışmada, bir otomobil ısı pompası sisteminde R152a soğutucu akışkanının kullanımı farklı hava sıcaklık ve hızlarında test edilmiştir. Deneylerde iç ve dış üniteye (yoğuşturucu ve buharlaştırıcı) giren hava akımı hız ve sıcaklıkları değiştirilerek, sistemin 1sıtma durumundaki performansı belirlenmiştir. Klima ve 1sı pompası sistemlerinde yaygın olarak kullanılan R134a soğutucu akışkanı çalışma şartları ile R152a'nın çalışma şartları karşılaştırılmıştır. Sonuç olarak, R152a soğutucu akışkanı ile çalıştırılan sistemin 1sıtma kapasitesinin R134a'ya göre daha yüksek olduğu belirlenmiştir. İç ünite girişindeki hava debisinin artmasıyla ile R152a'nın 1sıtma kapasitesi değerlerinin azaldığı görülmüştür. Ayrıca, hava akış şartlarının performansa olan etkisinin sıcaklık şartlarına göre daha yüksek olduğu belirlenmiştir. R152a'nın gerekli iyileştirmeler yapıldığında otomobil iklimlendirme sistemlerinde uygun alternatif bir soğutucu akışkan olabileceği belirlenmiştir.
\end{abstract}

Anahtar Kelimeler: R134a, R152a, otomobil 1s1 pompas1 sistemi

\section{Influence of air temperature and flow conditions on the system performance in the use of R152a in automobile heat pump systems}

\begin{abstract}
In this study, the use of R152a in an automobile heat pump system was experimentally investigated under different air temperatures and air flow rates. System performance was determined by changing the air flow rates and temperatures entering the indoor and outdoor units. Operating conditions of R134a and R152a, which used in air conditioning and heat pump systems, are compared. It was determined that the heating capacity of the $\mathrm{R} 152 \mathrm{a}$ was higher than that of R134a. It was also seen that the heating capacity of R152a increased with the decreased of the air flow rates at the indoor unit. Besides, it was observed that the effect of air flow conditions on the performance parameters was higher than environmental conditions. Finally, it was determined that R152a can be used as an alternative refrigerant in automotive air conditioning systems when the necessary improvements made.
\end{abstract}

Keywords: R134a, R152a, automobile heat pump system

\section{Giriş}

Hidroflorokarbon (HFC) grubu soğutucu akışkanların yüksek Küresel Isınma Potansiyeli (GWP) değerleri nedeniyle çevreye verdikleri zararlardan dolayı alternatif soğutucu akışkanların kullanımları ile ilgili çalışmalar devam etmektedir. Mobil iklimlendirme sistemlerinde yaygın olarak kullanılmakta olan R134a'nın GWP değeri 1300 olup Avrupa Birliği direktifleri tarafından kullanımına sinırlamalar getirilmektedir (2014/517/EU). Bu kapsamda, Avrupa Birliği direktifleri GWP değeri 150'nin altında olan soğutucu akışkanların kullanımına müsaade etmektedir. R134a'nın düşük GWP değerine sahip en önemli alternatiflerinden olan Hidrofloroolefin (HFO) grubundan R1234yf ve R1234ze(E) soğutucu akışkanlarının fiyatlandırması R1234yf (110-150 USD/kg) ve R1234ze( 35- 
$50 \mathrm{USD} / \mathrm{kg}$ ) aralığında değişmektedir. Bunlara ilaveten Dünya üzerinde $\mathrm{HFO}$ soğutucu akışkanlarını üreten iki büyük üretici olduğu düşünüldüğünde yeni alternatiflerin bulunması şarttır (Ciconkov R., 2018).

R152a'nın GWP değerlerine bakıldığında R134a'dan düşük olduğu, Avrupa Birliği direktifinin sınırları içerisinde değerlendirilebileceği görülmektedir (Tablo 1). $\mathrm{Bu}$ nedenle R134a kullanılan sistemlerde farklı soğutucu akışkan kullanılması düşünüldüğünde R152a ön plana çıkmaktadır. Literatürde R152a'nın iklimlendirme sistemlerinde kullanımı ile ilgili yapılan çalışmalardan bazıları aşağıda sıralanmıştır.

Tablo 1. Soğutucu akışkan özellikleri $25^{\circ} \mathrm{C}$ (Lemmon vd., 2014).

\begin{tabular}{|c|c|c|}
\hline Özellikler & $\mathrm{R} 134 \mathrm{a}$ & $\mathrm{R} 152 \mathrm{a}$ \\
\hline $\begin{array}{l}\text { ASHRAE Güvenlik } \\
\text { Sınıflandırması }\end{array}$ & A1 & A2 \\
\hline $\mathrm{ODP}$ & 0 & 0 \\
\hline GWP & 1300 & 124 \\
\hline Kritik sicaklık (K) & 247,08 & 386,41 \\
\hline Kritik basınç $(\mathrm{kPa})$ & 4059,28 & 4516,8 \\
\hline $\begin{array}{l}\text { Buhar yoğunluğu }\left(\mathrm{kg} \cdot \mathrm{m}^{-3}\right) \\
25^{\circ} \mathrm{C}\end{array}$ & 32,35 & 18,47 \\
\hline Siv1 yoğunluğu $\underset{{ }^{\circ} \mathrm{C}}{\left(\mathrm{kg} \cdot \mathrm{m}^{-3}\right) 0}$ & 1294,8 & 959,11 \\
\hline $\begin{array}{l}\text { Gizli buharlaşma 1sısı } \\
\left(\mathrm{kJ}^{\left.-\mathrm{kg}^{-1}\right)}\right.\end{array}$ & 198,72 & 279,36 \\
\hline
\end{tabular}

Ghodbane (1999), çalışmasında R134a kullanan buhar sıkıştırmalı soğutma çevriminde alternatif olarak R152a'y1 test etmiş ve soğutma tesir katsayısı (STK) değerinin R134a'ya göre \%15 oranında daha yüksek olduğunu belirlenmiştir. Scherer vd., (2003), R134a ile R152a soğutucu akışanlarını buhar sıkıştırmalı mekanik soğutma çevriminde test etmiş ve birbirine yakın performans değerleri elde etmişlerdir. Meng vd., (2016) bir otomobil iklimlendirme sisteminde, R134a'nın alternatifi olarak düşük
GWP değerine sahip R1234ze(E) ve R152a soğutucu akışkanlarının karışımlarının kullanılması durumunda performans parametrelerinin değişimlerini incelemişlerdir. R134a ile karşılaştırıldığında en yüksek değerlerin karışımın \%50 R1234ze(E)/\%50 R152a olduğu durumda elde edildiğini belirlemişlerdir.

Hoşöz vd., (2015) yaptıkları çalışmada faklı 1S1 kaynaklar1 kullanabilen bir 1s1 pompas1 sisteminde R134a'y1 test etmişlerdir. Is1 kaynağı olarak motor soğutma suyunun kullanılması ile en iyi performans değerlerinin elde edildiğini tespit etmişlerdir. Wang vd., (2017) soğutucu akışkan olarak $\mathrm{CO}_{2}$ kullanılan bir 1s1 pompas1 sistemini test etmişlerdir. Dış ortam hava sıcaklığının -20 ${ }^{\circ} \mathrm{C}$ olmasi durumunda 1sitma tesit katsayısını (ITK) 3,1 1sitma kapasitesini ise 3,6 kW olarak hesaplamışlardır. Lee vd., (2016) otomobil 1sı pompası ile gerçekleştirdikleri testlerde $-10{ }^{\circ}$ C'nin altında dış hava sicaklıklarında 1s1 pompasının yardımcı bir sistemle birlikte çalışmasının uygun olacağını ifade etmişlerdir. Bu sonuçlara benzer olarak, Wanga vd., (2017) otomobil 1s1 pompas1 sistemi üzerinde yaptıkları deneylerde dış hava sıcaklıklarının $-18^{\circ} \mathrm{C}$ altında olduğu durumlarda sistemin 1sitma kapasitesinin yetersiz kaldı ğını tespit etmişlerdir. Meng vd., (2018) R1234yf'ye \% 11 oranında R134a ilave ederek elde ettikleri karışımı bir otomobil iklimlendirme sisteminde test etmişlerdir. R1234yf/R134a karışımından elde edilen 1sitma kapasitesinin ve COP değerlerinin R134a ya kıyasla sirasıyla \% 3 ve \% 4-16 daha düşük olduğunu tespit etmişlerdir. Karışımının volumetrik veriminin ise R134a'ya göre \% 5 daha yüksek olduğunu belirlemişlerdir. Literatür incelendiğinde R152a'nın otomobil iklimlendirme sistemlerinde kullanım ile ilgili yapılan çalışmaların yeterli olmadığı ve hava hız ve sıcaklıklarının sistem performansına etkisinin kapsamlı olarak araştırılmadığ anlaş1lmaktadır. $\mathrm{Bu}$ çalışmada otomobil 
iklimlendirme sistemine eşdeğer olarak kurulan bir otomobil 1S1 pompasi deney sisteminde R134a ve R152a soğutucu akışkanlarının kullanımı ısıtma durumu için değerlendirilmiştir. Otomobil 1S1 pompası sisteminde R152a kullanılması durumunda çevre sıcaklığı ve hava akış şartlarının sistem performansı üzerine etkileri deneysel olarak belirlenmiştir.

\section{Materyal ve Metot}

\subsection{Deney Sisteminin Tanıtımı}

Deneysel otomobil 1sı pompası sistemi klasik bir otomobil klima sistemi oluşturulmuştur.

Sistemin 1sıtma amaçlı kullanılabilmesi amaciyla dört yollu valf ve çeşitli vanalar eklenmiştir (Şekil 1). Tablo 2'de sistemi oluşturan ekipmanların özellikleri incelenebilir.

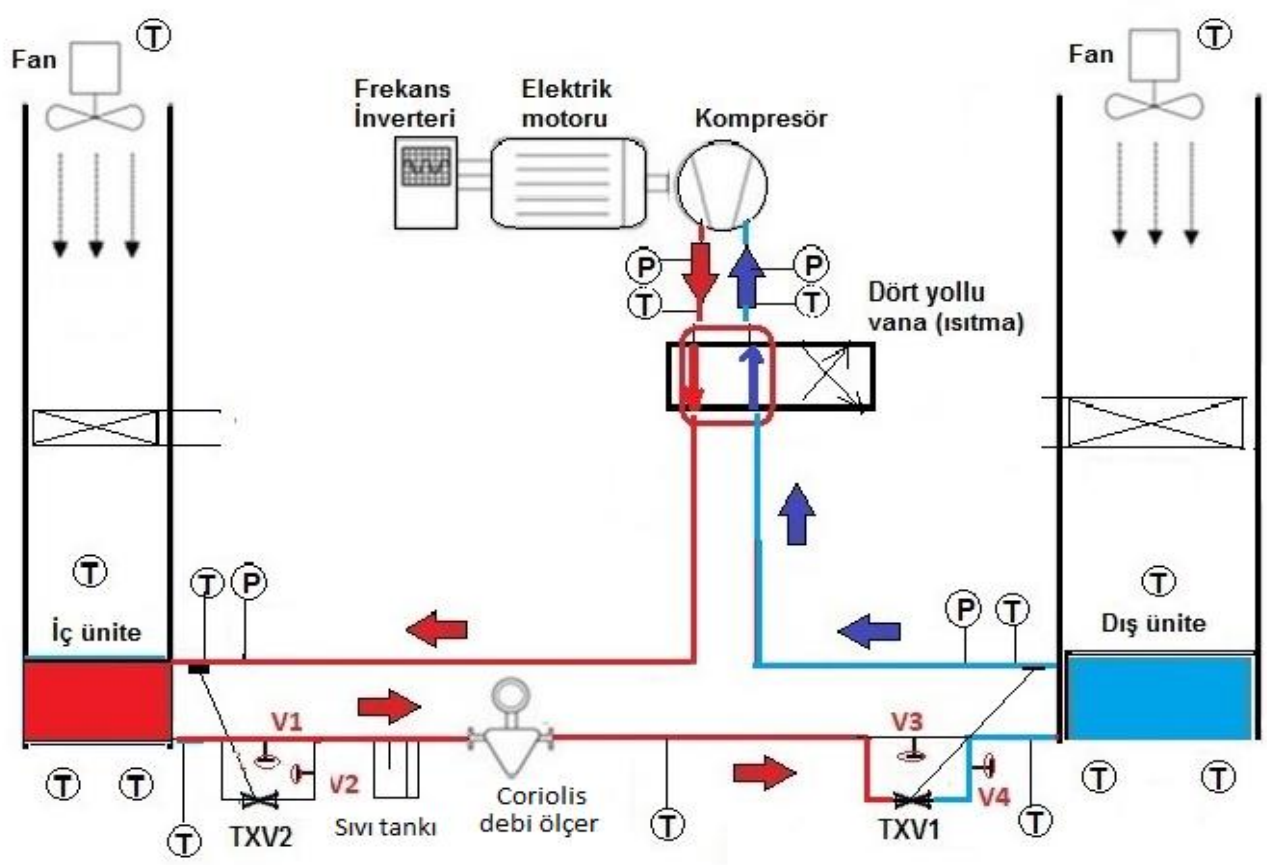

Şekil 1. Deneysel 1s1 pompas1 sisteminin genel görünümü.

Is1 pompas1 sisteminin 1sitma modunda çalı̧̧ması durumunda soğutucu akışkan akımının izlediği yollar Şekil 1'de verilmektedir. Isitma durumunda kompresörden çıkan soğutucu akışkan iç üniteye gönderilmekte iç ortama 1sısını vererek yoğuşturulmaktadır. İç üniteden geçen soğutucu akışkan kapalı durumda olan TXV2'yi py-pass ederek siv1 tankına gelmektedir. Daha sonra kütlesel debi ölçerden geçen soğutucu akışkan TXV1'e gelmekte ve basıncı ve sıcaklığı düşürülerek, dış üniteye girmektedir ( $\mathrm{Bu}$ durumda V3 kapalı V4 valfi ise açıktır).
Soğutucu akışkan dış ünitede çevre havasından 1sı çekerek buharlaşmakta en son olarak kompresör girişine yönlendirilmekte ve çevrimini tamamlamaktadır (Şekil 1). İç ve dış ünite kanalları içine istenilen hava akımı sıcaklıklarını sağlamak amacıyla elektrikli 1sitıcılar ve hava kanallarının girişine istenen hava akımı hızlarını sağlamak için ayarlanabilir fanlar yerleştirilmiştir. Bağlantı elemanı olarak, buhar ve siv1 hattında bakır borular kullanılmıştır. Bağlantı elemanları çaplarına uygun yalıtım malzemesi ile yalıtılmıştır. 
Tablo 2. Deneysel sistemde kullanılan ekipmanların özellikleri.

\begin{tabular}{|c|c|}
\hline Ekipman & Özellikler \\
\hline $\begin{array}{c}\text { Kompresör } \\
\text { Dış ünite }\end{array}$ & $138 \mathrm{cc}$, Silindir sayısı: 5 \\
\hline $\begin{array}{c}\text { (buharlaştırıc1) } \\
\text { İçnite }\end{array}$ & $580 \times 350 \times 20 \mathrm{~mm}^{3}$ \\
\hline (yoğusturucu) & $220 \times 260 \times 60 \mathrm{~mm}^{3}$ \\
\hline Kısılma Vanası & TXV $(5,27 \mathrm{~kW})$ \\
\hline
\end{tabular}

Sistemde dolaşan soğutucu akışkanın sıcaklıkları her bir bileşenin giriş ve çıkış noktalarından $\mathrm{K}$ tipi thermokuplar kullanılarak ölçülmüştür. Ölçülen değerler veri toplama cihazı ile bilgisayara aktarılmıştır. Sistemde basınç ölçümü buharlaşma ve yoğuşma basıncı olmak üzere iki noktadan dijital manifold ile yapılmıştır. Soğutucu akışkanın kütlesel debisi Coriolis tipi debimetre ile ölçülmüştür. Ölçüm cihazlarına ait hassasiyetler Tablo 3'de verilmektedir. Soğutucu akışkanların termofiziksel özellikleri ve entalpileri REFPROP 9.1 programından alınmıştır (Lemmon vd.,2014). Deneysel çalışmada soğutucu akışkanların Tablo 1'de belirtilen sıv1 haldeki yoğunluklarına bağlı olarak R134a'dan 575 g, R152a'dan 425 g soğutucu akışkan yüklenmiştir. Deneylerde diş üniteye giren hava akımının sicaklığ $17^{\circ} \mathrm{C}$, iç üniteye giren hava akımının sicaklığı ise $7 / 15 / 20^{\circ} \mathrm{C}^{\prime}$ de sabit tutulmuştur. Kompresör devri 750 ve $2750 \mathrm{~d} / \mathrm{d}$ arasinda $500 \mathrm{~d} / \mathrm{d}$ artışlarla değiştirilerek deneyler yapılmıştır. Deneylerde çevresel ortam ile dengeli hale getirildikten sonra ölçümler alınmıştır. Çevrimin performansının ölçülmesinde kullanılan ana veriler sıcaklık, basınç ve kütlesel debidir. Ölçüm cihazlarına ait hassasiyet ve ölçüm aralığı değerleri Tablo 3'de verilmiştir.
Tablo 3. Kullanılan Ölçüm Cihazlarının Özellikleri

\begin{tabular}{|c|c|c|c|}
\hline $\begin{array}{c}\text { Ölçülen } \\
\text { değer }\end{array}$ & Ölçüm cihazı & $\begin{array}{c}\text { Ölçüm } \\
\text { aralığı }\end{array}$ & Doğruluk \\
\hline Sıcaklık & $\begin{array}{c}\text { K-tip } \\
\text { termokupl }\end{array}$ & $\begin{array}{c}-100- \\
1370{ }^{\circ} \mathrm{C}\end{array}$ & $\pm 0,8^{\circ} \mathrm{C}$ \\
\hline Basınç & $\begin{array}{c}\text { Elektronik } \\
\text { Manifold }\end{array}$ & $\begin{array}{c}-1-60 \\
\text { bar }\end{array}$ & $\pm \% 0,5$ \\
\hline $\begin{array}{c}\text { Hava akış } \\
\text { oranı }\end{array}$ & $\begin{array}{c}\text { Anemometre } \\
0-30 \\
\mathrm{~ms}^{-1}\end{array}$ & $\pm \% 2$ \\
\hline $\begin{array}{c}\text { Soğutucu } \\
\text { akışkan } \\
\text { debisi }\end{array}$ & $\begin{array}{c}\text { Coriolis } \\
\text { kütlesel debi } \\
\text { ölçer }\end{array}$ & $\begin{array}{c}0-5 \mathrm{~kg} \\
\mathrm{~s}^{-1}\end{array}$ & $\pm \% 0,1$ \\
\hline $\begin{array}{c}\text { Güç } \\
\text { Pompresör } \\
\text { hızı }\end{array}$ & $\begin{array}{c}\text { Frekans } \\
\text { inverteri }\end{array}$ & $\begin{array}{c}10-50 \\
\mathrm{~Hz}\end{array}$ & $\pm \% 0,2$ \\
\hline
\end{tabular}

\subsection{Termodinamik Analizi}

Deneysel 1s1 pompas1 sisteminin 1sitma çevrimi olarak çalıştırılması durumunda kullanılan enerji denklemleri aşağıda verilmektedir. Sistemden iç ortama verilen ısıtma kapasitesi aşağıdaki denklem kullanılarak hesaplanır.

$\dot{\mathrm{Q}}_{\text {Isıtma }}=\dot{\mathrm{m}}_{\mathrm{r}}\left(\mathrm{h}_{\mathrm{i} \text { u̧ ünite,g }}-\mathrm{h}_{\text {iç ünite,ç }}\right)$

Kompresörün adyabatik olarak çalıştığı kabul edilirse, kompresörde soğutucu akışkana verilen güç aşağıdaki denklem kullanılarak bulunur.

$\dot{\mathrm{W}}_{\mathrm{komp}}=\dot{\mathrm{m}}_{\mathrm{r}}\left(\mathrm{h}_{\mathrm{komp}, \mathrm{c}}-\mathrm{h}_{\mathrm{komp}, \mathrm{g}}\right)$

Enerji etkenliğinin bir göstergesi olan 1sıtma tesir katsayısı ise, soğutma kapasitesinin kompresör gücüne oranlanması ile aşağıdaki denklem kullanılarak bulunur.

$\mathrm{ITK}=\dot{\mathrm{Q}}_{\text {Isıtma }} / \dot{\mathrm{W}}_{\text {komp }}$ 


\section{Bulgular}

Şekil 2-5 arasında otomobil 1S1 pompas1 sisteminde soğutucu akışkan olarak R152a kullanılması durumunda performans parametrelerinin kompresör devrine ve hava akış şartlarına bağlı değişimleri verilmektedir. Tüm testlerde dış ünite girişindeki hava akımı sıcaklığ $7{ }^{\circ} \mathrm{C}$ 'dir. İç ünite girişindeki hava akımı sıcaklığı ise 7,15 ve $20{ }^{\circ} \mathrm{C}$ olarak değiştirilmiştir. Tüm testlerde diş üniteye giren hava akımı hızı 2,6 m/s'dir. İç üniteye giren hava debisi en düşük 232,9 $\mathrm{m}^{3} / \mathrm{h}$, maksimum hava debisi değeri ise $698,8 \mathrm{~m}^{3} / \mathrm{h}$ olarak araç içi kabin şartları düşünülerek belirlenmiştir.

\subsection{R152a ve R134a soğutucu akışkanlarının iç ve dış üniteye giren hava akımı sıcaklıklarının sabit olmast durumunda karşılaştırılması}

$\mathrm{Bu}$ testlerde, iç ve dış üniteye giren hava akımı sıcaklıkları sırasıyla $20{ }^{\circ} \mathrm{C}$ ve $7{ }^{\circ} \mathrm{C}$, iç ünite hava debisi $232,9 \mathrm{~m}^{3} / \mathrm{h}$, diş üniteye giren hava akımının hızı 2,6 m/s'dir. İç ünite hava sıcaklığı araçlarda yolcu kabini dönüş havası sıcaklığına yakın bir değer olarak $20{ }^{\circ} \mathrm{C}$ seçilmiştir. Tablo 4'de test şartları verilmiştir.

Tablo 4. R134a ve R152a karşılaştırma test şartları

\begin{tabular}{|c|c|}
\hline Özellik & Set değerleri \\
\hline $\begin{array}{c}\text { Kompresör Devri } \\
(\mathrm{d} / \mathrm{d})\end{array}$ & $\begin{array}{c}750-2750(500 \mathrm{~d} / \mathrm{d} \\
\text { aralıkla })\end{array}$ \\
\hline $\begin{array}{c}\text { Tiç,h,g }\left({ }^{\circ} \mathrm{C}\right) \\
\text { Tdış,h,g }\left({ }^{\circ} \mathrm{C}\right)\end{array}$ & 20 \\
\hline $\begin{array}{c}\text {.Soğutucu } \\
\text { akışkanlar }\end{array}$ & 7 \\
\hline $\begin{array}{l}\text { Viç,h,g }\left(\mathrm{m}^{3} / \mathrm{h}\right) \\
\text { Rdış,h,g }(\mathrm{m} / \mathrm{s})\end{array}$ & $234 \mathrm{a}, \mathrm{R} 152 \mathrm{a}$ \\
\hline
\end{tabular}

Şekil 2'de soğutucu akışkanların P-h diyagramında şematik gösterimi karşılaştırmalı olarak verilmiştir. Şekil 2 incelendiğinde eşdeğer basınçta birim kütle değeri için R152a'nın buharlaşma gizli 1sısının, evaporatörde buharlaşırken özgül entalpisindeki farkın R134a' ya göre yaklaşık \%55 daha yüksek olduğu görülmektedir. Özgül entalpi farklarının yüksek olması R152a'dan elde edilen 1sitma kapasitesi değerlerinin R134a'ya kıyasla daha yüksek olmasını sağlamaktadır. Şekil 3 (a), (b), (c) 'de R152a ve R134a kompresör devirlerine bağlı olarak performans parametrelerinin değişimleri verilmiştir. Şekil 3 (a)'da isıtma kapasitesinin kompresör devriyle arttı̆ 1 görülmektedir. Kompresör devirlerinin artmasiyla R152a'dan elde edilen 1sitma kapasitesindeki artışın R134a'ya göre daha yüksek olduğu görülebilir.

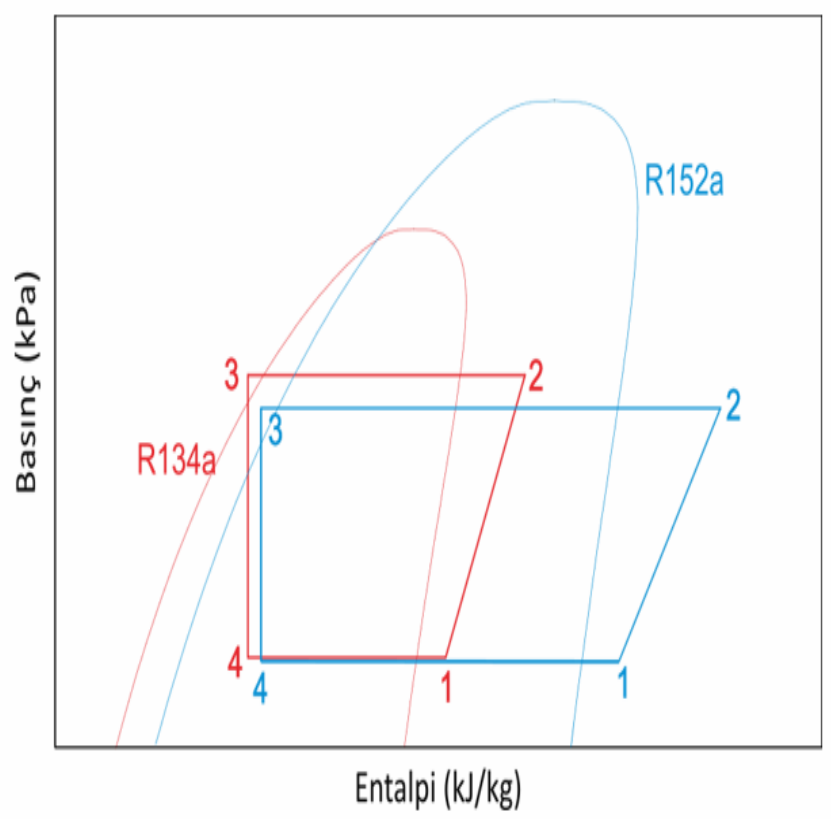

Şekil 2. Soğutma çevriminin R134a ve R152a için P-h diyagramında şematik gösterimi.

Kompresör gücü, kompresör devrinin artması ile soğutucu akışkan debisinin artması ve buharlaştırıcı basıncının düşüp, yoğuşturucu basıncının yükselmesi sonucu artmaktadır. R152a için kompresörde soğutucu akışkana verilen güç değerlerinin R134a'ya kıyasla daha yüksek olduğu görülmektedir (Şekil 3 b). Ayrıca, yüksek devirlerde aradaki farkın arttığı incelenebilir. Kompresör devrine bağl1 
olarak ısıtma tesir katsayısının (ITK) değişimi Şekil 3 (c)'de verilmektedir. ITK, 1sıtma kapasitesinin kompresör gücüne oranıdır. Kompresör devrinin artmasiyla ITK değerlerinin azaldığı görülmektedir. Bunun nedeni kompresör devrinin artmasıyla kompresör gücündeki artışın 1sıtma kapasitesindeki artışa göre daha yüksek olmasıdır. Soğutucu akışkan kütlesel debisine bağlı olarak kompresör güç değerleri daha fazladır bu durum ITK değerinin azalmasına neden olmaktadir.

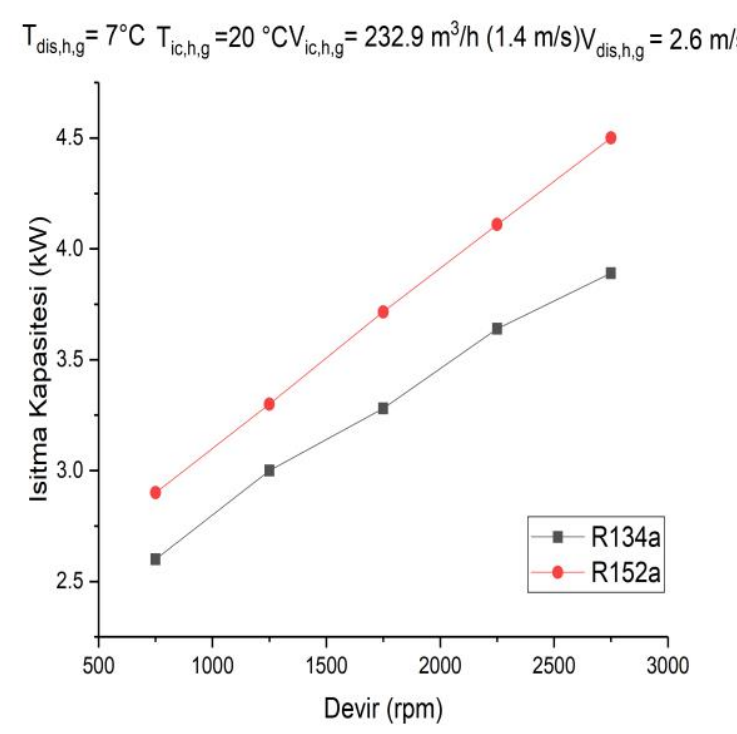

(a)

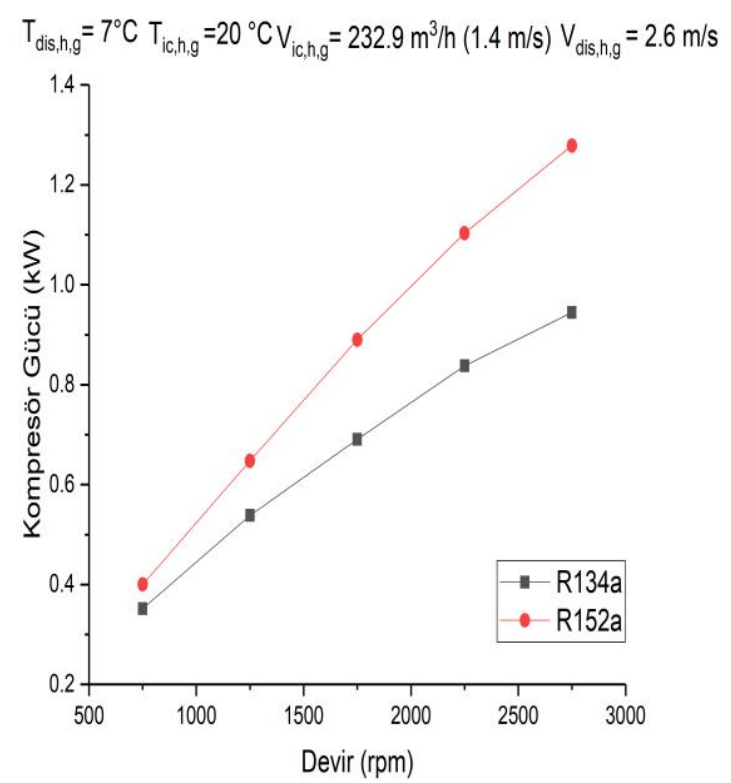

$T_{\text {dis, }, \mathrm{g}}=7^{\circ} \mathrm{C} T_{\text {ich, }, g}=20^{\circ} \mathrm{C} V_{\text {ich, }, g}=232.9 \mathrm{~m}^{3} / \mathrm{h}(1.4 \mathrm{~m} / \mathrm{s}) V_{\text {dis, h,g }}=2.6 \mathrm{~m} / \mathrm{s}$

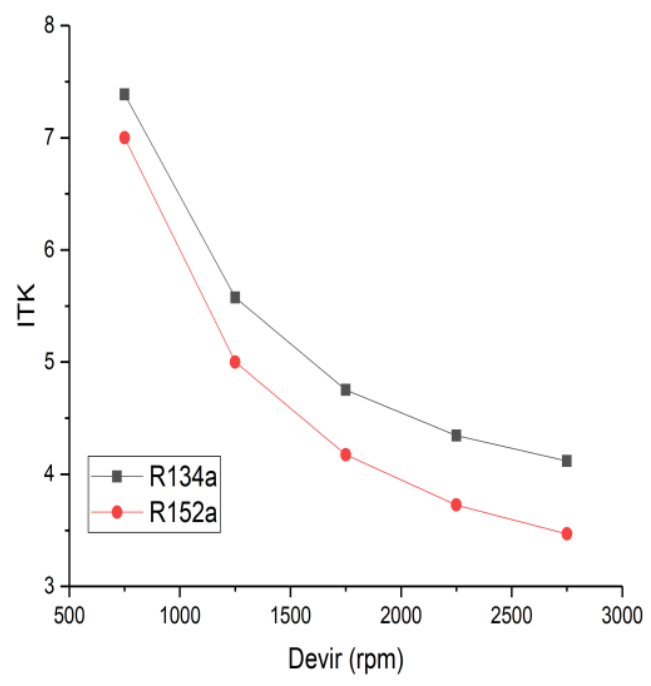

(c)

Şekil 3. Kompresör devrine bağlı olarak a) 1sitma kapasitesi b) kompresör gücü c) ITK değerlerinin değişimi.

\subsection{Hava sicaklı̆̆ının sistem performansı üzerine etkisi}

İç üniteden (yoğuşturucu) geçen hava akımı sıcaklığının performans parametreleri üzerine etkisi farklı kompresör hızları için Şekil 4 (a), (b), (c)'de verilmektedir. İç üniteden geçen hava akımı sıcaklığı sırasıyla 7,15 ve $20^{\circ} \mathrm{C}$ 'de olarak seçilmiştir. Şekil 4 (a) ve (b) incelendiğinde, kompresör devirlerinin ve iç üniteye giren hava sıcaklıklarının artmasıyla 1sıtma kapasitesi ve kompresör güçlerinin arttığ1 görülmektedir. Tablo 5'de test şartları verilmiştir.

(b) 
Tablo 5. Hava sıcaklığının sistem performansı üzerine etkisi test şartları.

\begin{tabular}{|c|c|}
\hline Özellik & Set değerleri \\
\hline Kompresör Devri (d/d) & $750-2750(500 \mathrm{~d} / \mathrm{d}$ aralık $)$ \\
\hline Tiç,h,g $\left({ }^{\circ} \mathrm{C}\right)$ & $7 / 15 / 20$ \\
\hline $\mathrm{Td} 1 s ̧, \mathrm{~h}, \mathrm{~g}\left({ }^{\circ} \mathrm{C}\right)$ & 7 \\
\hline Soğutucu akışkanlar & $\mathrm{R} 152 \mathrm{a}$ \\
\hline Viç,h,g $\left(\mathrm{m}^{3} / \mathrm{h}\right)$ & $232,9 \mathrm{~m}^{3} / \mathrm{h}$ \\
\hline $\mathrm{Vd}_{1}$ ș,h,g $(\mathrm{m} / \mathrm{s})$ & $2,6 \mathrm{~m} / \mathrm{s}$ \\
\hline
\end{tabular}

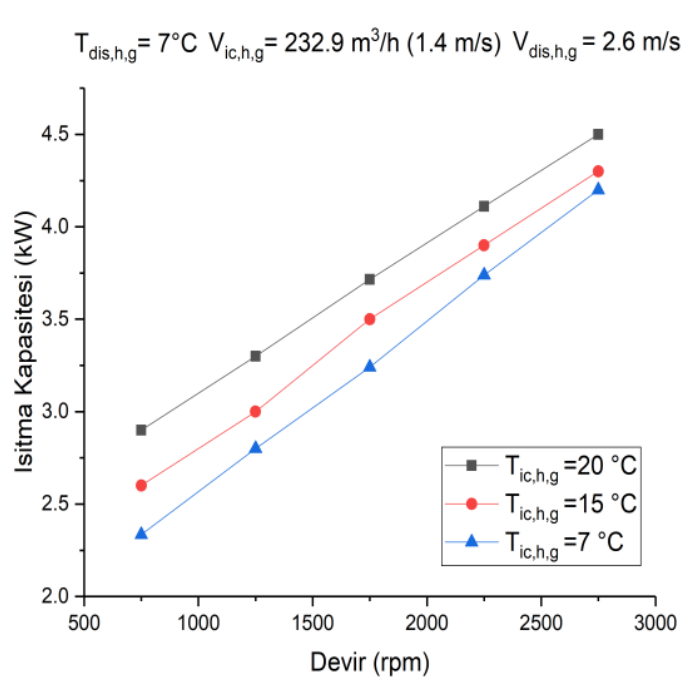

(a)

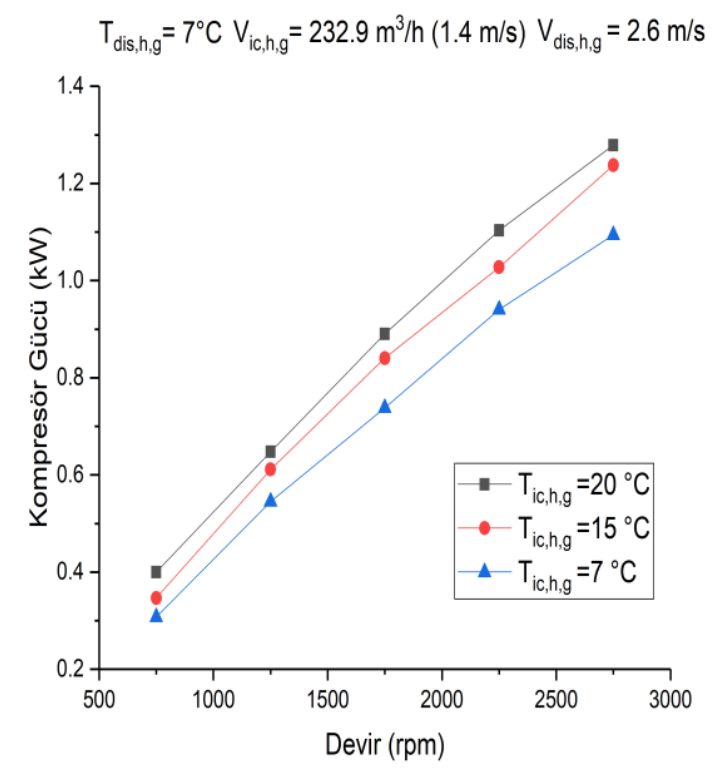

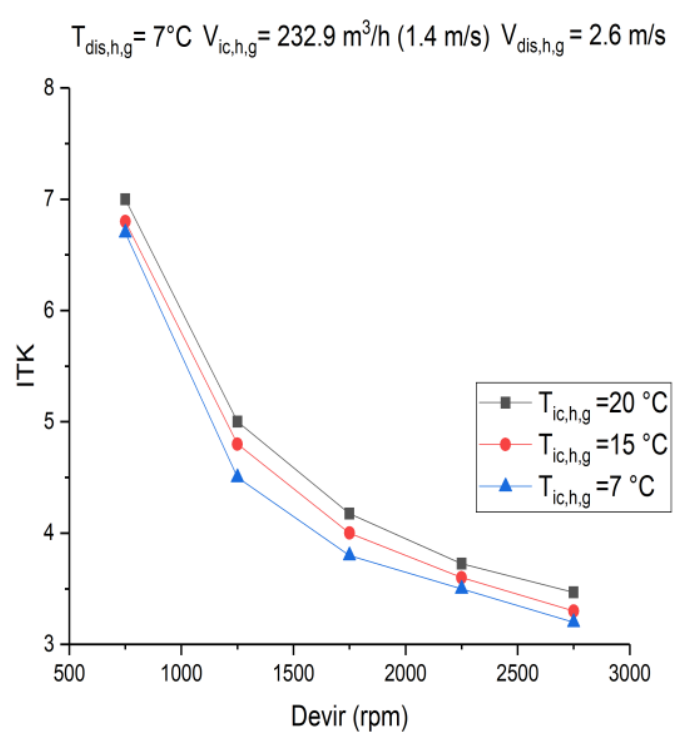

(c)

Şekil 4. Kompresör devrine ve hava sıcaklıklarına bağlı olarak a) 1sitma kapasitesi b) kompresör gücü c) ITK değerlerinin değişimi.

İç üniteden geçen hava akımı sıcaklıklarının yükselmesiyle soğutucu akışkan ile hava akımı arasındaki sıcaklık farkının artmasından dolayı kompresördeki basınç farkı yükselir. Bunun sonucu olarak, soğutucu akışkan debisinin artmasiyla 1sitma kapasitesi değerleri artar. Isıtma kapasitesindeki değişimin sıcaklık farkından çok devir sayısı ile ilişkili olduğu görülmektedir.

(b) 


\subsection{Hava akış şartlarının sistem performanst üzerine etkisi}

Soğutucu akışkan olarak R152a kullanılması durumunda hava akış şartlarının performans üzerine etkisi Şekil 5 (a), (b), (c)'de verilmektedir. Hava debisi değerleri azaldıkça 1sitma kapasitesinin ve kompresörde soğutucu akışkan verilen güç değerlerinin arttığı anlaşılmaktadır.

Tablo 6. Hava akış şartlarının sistem performansı üzerine etkisi test şartları.

\begin{tabular}{|c|c|}
\hline Özellik & Set değerleri \\
\hline Kompresör Devri (d/d) & $750-2750(500 \mathrm{~d} / \mathrm{d}$ aralık $)$ \\
\hline & \\
\hline Tiç,h,g $\left({ }^{\circ} \mathrm{C}\right)$ & 7 \\
\hline Tdiş,h,g $\left({ }^{\circ} \mathrm{C}\right)$ & 7 \\
\hline Soğutucu akışkanlar & $\mathrm{R} 152 \mathrm{a}$ \\
\hline & \\
\hline Viç,h,g $\left(\mathrm{m}^{3} / \mathrm{h}\right)$ & $232,9 / 399,34 / 698,8$ \\
\hline & \\
\hline Vdiş,h,g $(\mathrm{m} / \mathrm{s})$ & 2,6 \\
\hline
\end{tabular}

Şekil 5 (c)'de iç üniteye giren hava debisinin yükselmesiyle sistem ITK değerleri arttığ 1 görülmektedir. Kompresör güçlerindeki artışın 1sıtma kapasitedeki artıştan daha yüksek olmasından dolayı kompresör devrinin artmasıyla ITK değerleri azalmaktadır. Hava debisi arttırıldığında havanın sistemden çektiği enerji değerinin eşdeğer olarak artmadığı görülmüştür. Hava hızına bağlı olarak akışkanın enerji transfer etme süresinin kısalması olarak değerlendirilmektedir. Şartlandırılan havanın istenilen performansı sağlaması için $230 \mathrm{~m}^{3} / \mathrm{h}$ debideki havanın uygun olacağı görülmüştür. Çalışma şartlarında bu değer 232,9 $\mathrm{m}^{3} / \mathrm{h}$ olarak ölçülmüştür.

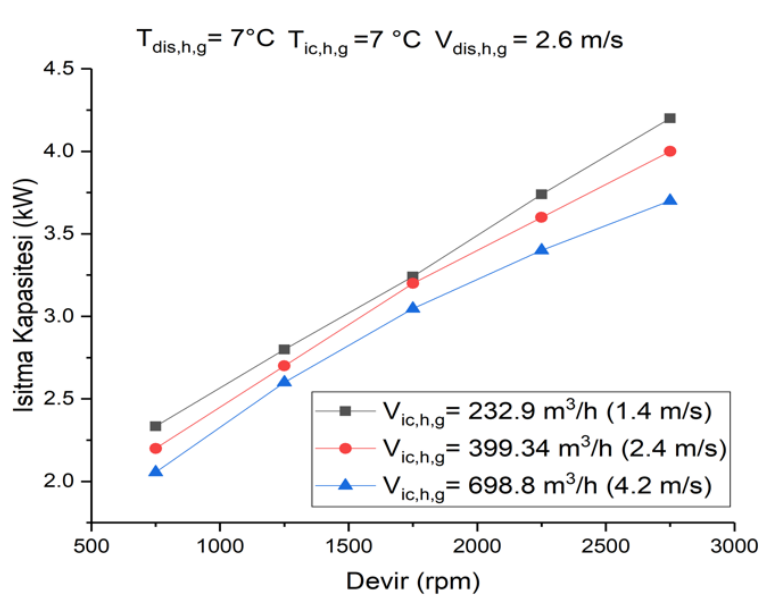

(a)

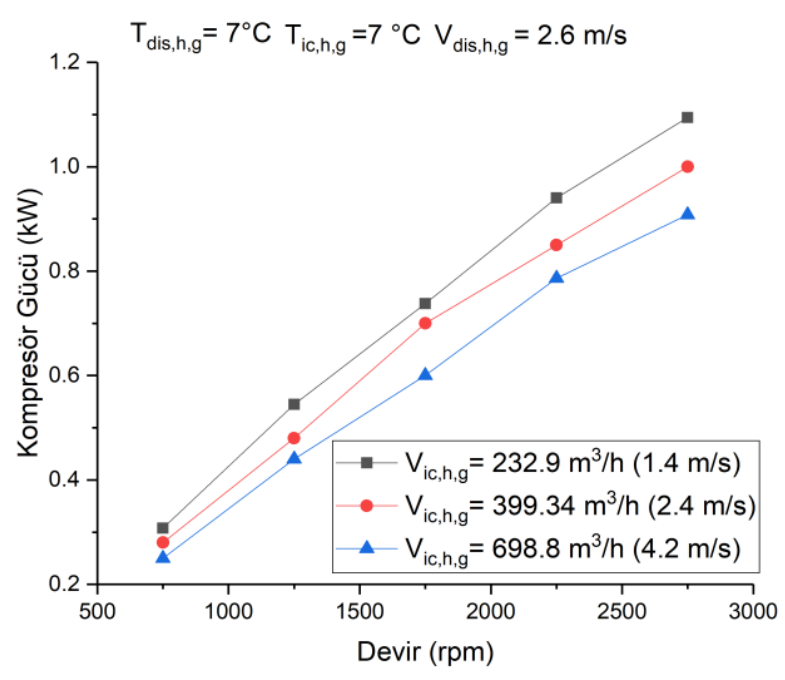

(b)

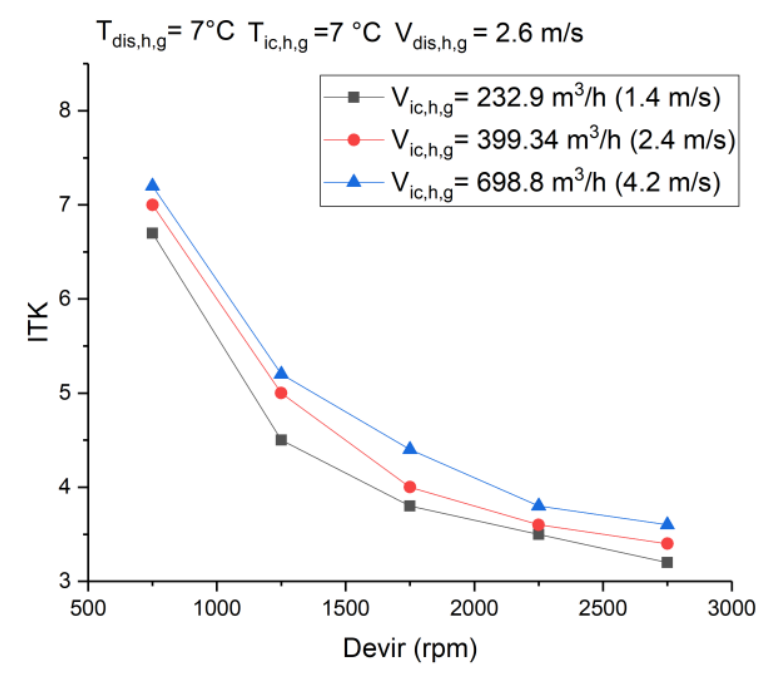

(c)

Şekil 5. Kompresör devrine ve hava akış şartlarına bağlı olarak a) 1sıtma kapasitesi b) kompresör gücü c) ITK değerlerinin değişimi. 


\section{Sonuç ve Tartışma}

$\mathrm{Bu}$ çalışmada, otomobil 1s1 pompası sisteminde R152a'nın kullanımı deneysel olarak incelenmiştir. Çalışma sonucu elde edilen sonuçlar ve değerlendirmeler aşağıda sunulmaktadır. R134a ile karşılaştırıldığında sistemde soğutucu akışkan olarak R152a kullanıldığında daha yüksek ısıtma kapasitesi değerlerine ulaşılmıştır. Kompresör devirlerinin artmasiyla R152a'dan elde edilen 1sıtma kapasitesindeki artışın R134a'ya göre daha yüksek olduğu belirlenmiştir. R152a için kompresör gücü değerlerinin R134a'ya kıyasla daha yüksek olduğu ve buna bağlı ITK değerlerinin daha düşük olduğu tespit edilmiştir. İç üniteye giren hava akımı debilerinin artmasıyla 1sitma kapasitesi ve kompresör güçlerinin azaldığı gözlenmiştir. Şartlandırılan havanın istenilen performansı sağlaması için $230 \mathrm{~m}^{3} / \mathrm{h}$ debideki havanın uygun olacağ1 görülmüştür. $\mathrm{Bu}$ sonuçlar doğrultusunda GWP değeri Avrupa Birliği direktiflerine uygun yanıcılık oranı ise diğer alternatif gazlar ile karşılaştırıldığında daha düşük olan R152a'nın gerekli iyileştirmeler yapıldığında otomobil klimalarına uygun alternatif bir soğutucu akışkan olabileceği düşünülmektedir.

\section{Teşekkür}

$\mathrm{Bu}$ çalışma Türkiye Bilimsel Ve Teknolojik Araştırma Kurumu (TÜBİTAK) Tarafından Desteklenmiştir. Proje Numarası: 216M437.

\section{Simge Listesi}

$\begin{array}{ll}\dot{Q} & \text { Kapasite }[\mathrm{kW}] \\ \dot{W} & \text { İş }[\mathrm{kW}] \\ \dot{m} & \text { Kütlesel debi }\left[\mathrm{kgs}^{-1}\right] \\ \mathrm{h} & \text { Entalpi }\left[\mathrm{kJkg}^{-1}\right] \\ \mathrm{T} & \text { Sicaklık }[\mathrm{K}] \\ \text { komp } & \text { Kompresör } \\ \text { evap } & \text { Evaporatör } \\ \text { kond } & \text { Kondenser } \\ \text { ç } & \text { Çı1kş } \\ \mathrm{h} & \text { Hava } \\ \mathrm{g} & \text { Giriş }\end{array}$

\section{Kaynaklar}

Ciconkov R., 2018, Refrigerants: There is still no vision for sustainable solutions, International Journal of Refrigeration, 86, 441-448.

European Parliament and of the Council, 2014 Regulation 2014/517/EU, Official Journal of the European Union: Fluorinated Greenhouse Gases, Strasbourg, EU.

Ghodbane, M., 1999. An Investigation of R152a and Hydrocarbon Refrigerants in Mobile Air Conditioning, SAE Technical Papers, Paper Code: 1999-010874.

Hosoz, M., Direk, M., Yigit, K. S., Canakci, M., Turkcan, A., Alptekin, E., Sanli, A., 2015, Performance Evaluation of an R134a Automotive Heat Pump System for Various Heat Sources in Comparison with Baseline Heating System, Applied Thermal Engineering, 78, 419-427.

Lee H., Lee M., 2016. Steady state and startup performance characteristics of air source heat pump for cabin heating in an electric passenger vehicle, International journal of refrigeration, 69, 232-242.

Lemmon, E.W., Huber, M.L., McLinden, M.O. 2014. REFPROP, NIST Standard Reference Database 23, v.9.1.National Institute of Standards. Gaithersburg.

Meng, Z., Zhang, H., Qiu, J., Lei, M. (2016). Theoretical analysis of R1234ze (E), R152a, and R1234ze (E)/R152a mixtures as replacements of R134a in vapor compression system, Advances in Mechanical Engineering, 8(11), 1-10.

Meng Z., Zhang H., Lei M., Qin Y., Qiu J., 2018, Performance of low GWP $\mathrm{R} 1234 \mathrm{yf} / \mathrm{R} 134 \mathrm{a}$ mixture asa replacement for $\mathrm{R} 134 \mathrm{a}$ in automotive air 
conditioning systems, International Journal of Heat and Mass Transfer, 116, 362-370

Scherer, L.P., Ghodbane, M., Baker, J.A., Kadle, P.S. 2003. On-Vehicle Performance Comparison of an R-152a and R-134a Heat Pump System, SAE Technical Papers, Paper Code: 2003-010733.

Wanga Z., Wei M., Guo C., Zhao M., 2017. Enhance the heating performance of an electric vehicle AC/HP system under low temperature, Energy Procedia 105, 2384-2389

Wang D., Yu B., Hu J., Chen L., Shi J., Chen J., 2018. Heating performance characteristics of $\mathrm{CO}_{2}$ heat pump system for electrical vehicle in a cold climate, International Journal of Refrigeration, $85,27-41$. 